\title{
Satire and Efficacy in the Political Science Classroom
}

Rebecca A. Glazier, University of Arkansas at Little Rock

ABSTRACT Political satire has become increasingly prominent in recent years, leading some political science instructors to use satire in their courses. Yet, recent work suggests that political satire may encourage cynicism and decrease political efficacy. In this article, the author develops and tests an approach to teaching effectively with satire. Frequent use, source diversity, and critical evaluation engage students while allaying satire's potential detrimental effects. The author evaluates this pedagogical approach through a classroom experiment using both in-person and online classes (student $\mathrm{N}=163$ ). Qualitative and quantitative data offer suggestive evidence that refutes the warning that satire fundamentally depresses political efficacy and indicates that students enjoy satire and endorse its use. By deliberately using diverse satirical sources, instructors can maximize the benefits of satire while minimizing potential drawbacks. For interested instructors, the author's website contains a searchable catalog of satirical articles, video clips, and cartoons that can be used to teach specific political science concepts.

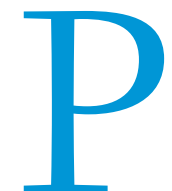
olitical satire is not only for the interior pages of the newspaper anymore. Far from the obtuse (or obvious) black-and-white cartoons of yesteryear, modern political satire garners the attention of millions of viewers each year (Bibel 2013; Gorman 2011). What does this mean for the political science classroom? Today, satire is more accessible than ever and students are more likely to be exposed to it (Baym 2005; Pew Research Center 2004). However, does it follow that using satire is a good pedagogical move? Does satire communicate a dystopic political message that dissuades students from participating in politics, or might it make the political world accessible, understandable, and even interesting?

The classroom strategies described in this article attempt to minimize the cynical effects of satire and bolster the feelings of understanding and engagement that it can provide through three teaching techniques: regularly using satire, using a variety of satirical materials, and emphasizing critical evaluation of satire. A teaching experiment in online and in-person classes indicated that this approach is likely to be well received and may actually improve political efficacy.

\section{THE PEDAGOGICAL RELEVANCE OF POLITICAL SATIRE}

Although satire has a long and important tradition in political commentary as a socially acceptable outlet for criticism of elites and the politically powerful (Duff 1936; Jones 2010; Mann 1973; Meddaugh 2010), it is sometimes difficult to identify. ${ }^{1}$ In fact,

Rebecca A. Glazier is an assistant professor in the department of political science at the University of Arkansas at Little Rock. She can be reached at raglazier@ualr.edu.
LaMarre, Landreville, and Beam (2009) found that interpretations of whether a work is considered satire are moderated by political ideology. The sometimes ironic effect is seen in studies like the one by Baumgartner and Morris (2008b), which found that Stephen Colbert's ultra-right-wing satire actually had a conservative effect on students. Drawing from the Oxford English Dictionary, the definition of satire used in this article is "the use of humor, irony, exaggeration, or ridicule to expose and criticize incompetence or vices, particularly in the context of contemporary politics and other topical issues." By this definition, satire is a significant part of the political world that we encounter and construct daily (Edelman 1995; Ogborn and Buckroyd 2001).

Two of the most prominent satirical outlets today are Comedy Central's The Daily Show with Jon Stewart and The Colbert Report. These television programs are of particular interest to political science instructors in part because they are so popular with young people. The Pew Research Center for the People and the Press (2008) found that The Daily Show and The Colbert Report have the youngest audiences of any outlet in the survey (i.e., $74 \%$ to $80 \%$ of their audiences are 49 or younger); the same survey also reported that these viewers are tuning in primarily for entertainment (i.e., 53\% of Colbert's audience and $43 \%$ of Stewart's audience).

Beyond entertainment value, there is evidence that satire promotes learning. Scholars have found modest gains in the political knowledge of people watching late-night comedy and other "soft news" sources (Baek and Wojcieszak 2009; Baum 2003), and content analysis indicates that the political content of these programs is comparable to mainstream news (Fox, Koloen, and Sahin 2007; McBeth and Clemons 2011; Pew Research Center 
2008). Indeed, viewers of late-night satire are more informed about candidates and issue positions (Young 2004), and they are more knowledgeable about politics in general (Pew Research Center 2007) compared to those who do not view these programs. Similarly, Baumgartner and Morris (2006) found that watching The Daily Show increased confidence in a person's ability to understand politics; Moy, Xenos, and Hess (2005) found that late-night-comedy viewing boosts both the intent to vote and interpersonal political discussions; and Cao and Brewer (2008) found that exposure to political comedy is positively associated with political participation. For instructors who spend hours each week trying to teach political science to the core demographic of these programs, the overwhelming evidence that political satire can engage students is valuable information.

However, does the popularity of modern late-night satirical television programs-and their correlation with characteristics instructors would like to see in their students-mean that satire may be useful in the political science classroom? Many instructors are already teaching with satire; for instance: assigning Jon Stewart's satirical textbook (Baumgartner and Morris 2008a; Teten 2010), showing clips from The Daily Show (Beavers 2011), using political cartoons (Hammett and Mather 2010; Stark 2003), and discussing Saturday Night Live parodies (Journell 2011). Emerging research supports these efforts by suggesting that viewing satire has positive and significant effects on political participation (Cao and Brewer 2008; Hoffman and Thomson 2009; Hoffman and Young 2011) and attentiveness (Cao 2010), in addition to providing a nonthreatening medium through which to discuss important political issues (Cutbirth 2011; Lee 2012).

Yet, despite these positive indications, some research has been less enthusiastic, finding that satire's effects on learning are minimal (Baumgartner and Morris 2008a) and its effects on political efficacy are actually negative (Baumgartner 2008; Guggenheim, Kwak, and Campbell 2011; Tsfati, Tukachinsky, and Peri 2009). Baumgartner and Morris (2006) found that young people who watched The Daily Show's 2004 presidential-campaign coverage exhibited more cynicism toward the candidates, the electoral system, and the media. Other studies similarly found that viewers of satirical news pro-

\section{STRATEGIES FOR USING SATIRE}

The potentially alienating effects of satire are concerning. In an attempt to counter any negative effects on political efficacy, I adhere to three pedagogical principles when using satire in my courses. Used together, these strategies can maximize satire's benefits while avoiding its potential downsides. First, I use satire regularly. As with any teaching tool, it is best to incorporate satire as part of an overall teaching plan with clear goals in mind (Toohey 1999). Regularly using satire to address a variety of different topics in a deliberate-as opposed to an ad hoc-way may limit the negative impact of satire on efficacy. Moreover, the literature indicates that repeatedly exposing students to political satire may reduce the shock and subsequent cynicism some may experience when they first encounter sharp political criticism. For instance, Baumgartner and Morris (2006) found that the more self-reported exposure the respondents had to The Daily Show, the smaller was the effect of decreased efficacy. It is possible that viewers become accustomed to political criticisms and that the alienating effects of satire decline over repeated exposures. Thus, I try to incorporate satire into nearly every class meeting.

Second, I use a diverse selection of satirical materials. Although much of the scholarly research has focused on popular late-night satirical programs, there are many ways to use satire in the classroom. Whereas Baumgartner and Morris (2006) found a decrease in external political efficacy as a result of watching The Daily Show, a more diverse use of satire could yield a different result (Polk, Young, and Holbert 2009). It may be the particular approach of The Daily Show-namely, Jon Stewart's distinct style of juxtaposing statements by politicians and media outlets to point out hypocrisy and stupidity (Baym 2005; Jones 2005)-that fosters cynicism in viewers. Multiple satirical media, especially when analyzed thoroughly and repeatedly, are likely to provide a more diverse overall experience for students. For instance, Stephen Colbert's satire takes the form of parody, The Onion is sarcastic, and political cartoons often communicate complex and symbolic satirical messages (Conners 2005; Diamond 2002; Elder and Cobb 1983; Paletz 2002). I use all of these sources and more in my classes to present students with a varied range of satirical perspectives.

\section{Looking specifically at the effect of satire on political efficacy, the results indicate that by carefully selecting satire and thoughtfully incorporating it into courses, it is possible to minimize the negative effects and maximize the potential for political and educational benefits.}

grams exhibit greater cynicism (Tsfati, Tukachinsky, and Peri 2009) and distrust of politicians (Baumgartner 2008; Guggenheim, Kwak, and Campbell 2011).

The collective effect of these mixed studies may be the tempering of enthusiasm toward political satire as a teaching tool. If satire engages students in politics only to alienate them, then the endeavor is a wash or perhaps even, on balance, counterproductive. Thus, the purpose of the current study was to build on the growing literature by using an experiment to assess the value of satire as a teaching tool. Looking specifically at the effect of satire on political efficacy, the results indicate that by carefully selecting satire and thoughtfully incorporating it into courses, it is possible to minimize the negative effects and maximize the potential for political and educational benefits.
Third, I encourage students to critically engage with satire. An important difference exists between exposing students to satire and engaging them in critical evaluation of satire. Whereas the former may be helpful, the latter makes more pedagogical sense (Bean and Weimer 2011) and may be less likely to depress political efficacy. Because satire can sometimes be difficult to understand, critically engaging with it requires students to use higher-level thinking skills, which may actually result in greater critical thinking (Baumgartner and Morris 2008a). Indeed, because research shows that students have their own preconceptions when they interpret and experience satire (LaMarre, Landreville, and Beam 2009), engaging in critical analysis may draw out satire's best possible effects. Thus, in addition to critical discussions of satire in class, I require a satire writing assignment. For this assignment, students identify a piece of satire, 
write a one-page critical analysis that points out the political message in the satire and explains its meaning, and present it to the class. The goal of critical engagement is to encourage students not only to laugh at the jokes but also to think about why those particular political critiques might (or might not) be apt.

By teaching with satire using these three strategies-regularity, diversity, and critical analysis-in combination, I hope to avoid some of the declines in efficacy seen in prior studies. The following section describes how I evaluated these strategies through a teaching experiment.

\section{METHODS}

To assess the potential effects of satire on political efficacy, I used a teaching experiment comparing introductory political science classes taught using satire to those taught without satire. The experiment was conducted in seven courses from the fall of 2009 to the fall of 2011. Three courses taught with satire took place in person (Fall 2009, Fall 2010, and Fall 2011) and two took place online (Spring 2010 and Spring 2011). One control course-taught without satire-took place in person (Fall 2009) and one took place online (Fall 2011). The total number of students enrolled across all courses was 163 .

The control and satire classes were taught by the same professor using the same textbook and the same lectures; the satire condition also included satirical materials. These materials were selected to substantively complement the topics in the course. Examples of satire used in the course include the satirical news article "American People Ruled Unfit to Govern" (The Onion, April 14, 1999), which was an assigned reading for the unit on voting and elections; for a class on the scientific method, students watched the June 21, 2007, clip "Ron Paul's Colbert Bump" from The Colbert Report and were assigned to read Fowler's (2008) article on the Colbert Bump; the video clip "Funny or Die Presents: Playground Politics-Africa," available on YouTube, was used to illustrate resource disparities for a class on international political economy and the role of the International Monetary Fund; and the classic "Gerrymander" cartoon (Tisdale 1812) provided both a critique of redistricting and an illustration of its longevity. ${ }^{2}$

Incorporating discussion of the satire took about five minutes of each class meeting. In the control condition, the time was used for lecture or discussion. Students in the satire condition were also required to submit a one-page critical analysis of a piece of satire of their own choosing and to present it to the class. Students in the control condition were given a similar assignment to select, critically analyze, and present a current event. 3

At the beginning of the semester, students enrolled in both conditions took a presurvey to establish baseline measures on a variety of political attitudes. ${ }^{4}$ Of particular interest in this study is the battery of six political efficacy and trust-ingovernment questions, which have been included in the American National Election Studies since 1958 (Craig, Niemi, and Silver 1990). Possible scores on this battery range from 6 to 15. At the end of the semester, students took a postsurvey, which included the same questions about political efficacy and trust. Students in the satire condition were also asked questions regarding the use of satire in the class and were given space for open-ended responses. This research design allowed for the comparison of data within conditions (i.e., comparing the results of the surveys given at the beginning and at the end of the semester) and across conditions (i.e., comparing the results of the final surveys of both the experimental and control conditions). Teaching the satire and control conditions both in person and online also made it possible to evaluate whether the effects of satire change across platforms. The response rates were $97 \%(159 / 163)$ for the pretest and $79 \%(129 / 163)$ for the posttest.

To summarize, in the satire condition, students were regularly exposed to diverse forms of satire and encouraged to critically engage with the material through classroom discussions and oral and written assignments. The expectation was that using satire in this way would not lead to the declines in political efficacy identified in prior studies (Hypothesis 1). In addition, students were expected to respond positively to the satire (Hypothesis 2).

\section{RESULTS}

How valuable or risky is satire as a pedagogical tool in the political science classroom? One way to answer this question is to ascertain whether satire-used in a diverse, regular, and critical manner as described in this article-decreases political efficacy as expected. In this study, political efficacy was operationalized through a sixquestion battery; mean scores were then calculated for each class. The mean efficacy gains for the in-person, online, and total pooled classes are presented in figure 1.

As figure 1 illustrates, the general results across the classes in this study were consistent: levels of political efficacy were higher at the end of the semester than at the beginning. None of the classes experienced a negative change in political efficacy. The increase in efficacy was seen in both the satire and control conditions, which specifically indicates that using satire did not decrease student efficacy relative to either what it was before the class or the nonsatire environment. In fact, assessing efficacy gains in the in-person classes in particular revealed positive effects of the satire condition. In figure 1 , students in the in-person satire condition experienced almost a half-point gain in efficacy compared to a gain of slightly more than a tenth of a point for the in-person control condition. Taken together, the satire and control classes experienced an average efficacy gain of 0.4 and 0.28 , respectively. The online satire classes had an average efficacy gain of 0.24 compared to 0.49 for the in-person satire classes. The results of two-way t-tests indicated that the gains in

\section{Figure 1}

Gains in Political Efficacy Overall and across Instructional Medium

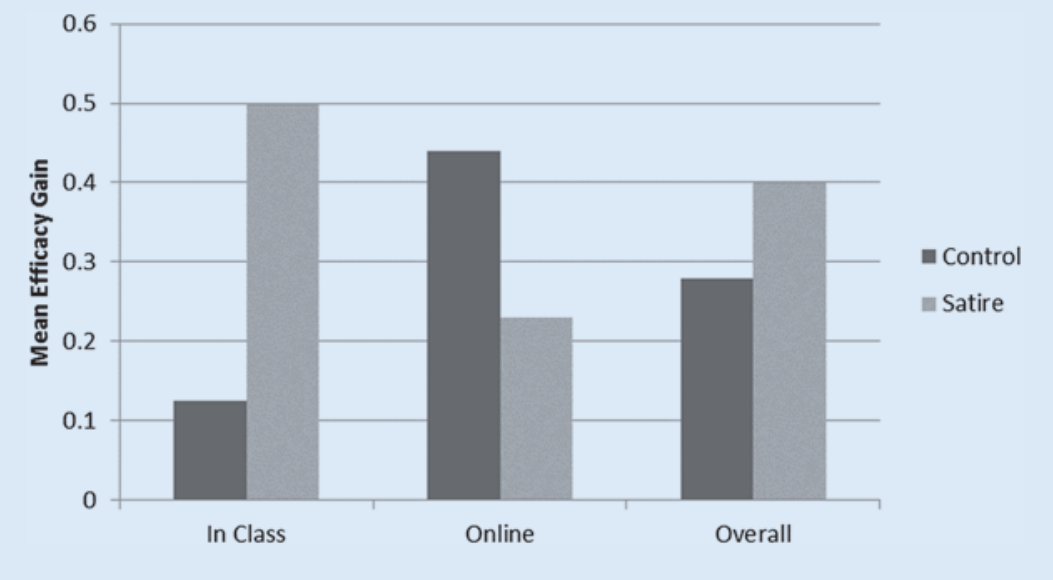


efficacy are statistically indistinguishable. Similarly, an ANOVA model accounting for both experimental condition (i.e., satire versus control) and course format (i.e., online versus in person) found no statistically significant differences in efficacy. 5

These tests support the conclusion that-counter to previous research-we need not fear a drop in efficacy as a result of teaching with satire. The data instead show consistent-although statistically insignificant-gains in political efficacy with the use of satire. Moreover, these results suggest that satire is as useful (or, possibly, as superfluous) online as it is in person. These findings may assuage some instructors who want to use satire in their classes but are concerned about its negative effects in terms of efficacy. At the same time, these data encourage instructors to be thoughtful in how satire is used, supporting Hypothesis 1 and the idea that the diverse, consistent, and critical use of satire does not harm students' political efficacy. from the in-person classes. Two-tailed t-tests were conducted to determine whether the differences between the in-person and the online classes were significant. For the two questions about satire helping students understand the material and making the class more enjoyable, the scores were significantly higher $(p<0.01)$ for in-person versus online classes. Students from both modes of instruction, however, were virtually unanimous in their recommendation that satire be used in future classes.

A close review of the qualitative and quantitative data indicates that variance in the student population and the mode of instruction may be the reason for these differences. It is certainly possible, and even likely, that there is an element to satire that is not easily communicated electronically. However, it also may be that online students are not accessing the satire as regularly. The average ages of the online and in-class students were 29.5 and 22.4, respectively.

\section{These tests support the conclusion that-counter to previous research-we need not expect a drop in efficacy as a result of teaching with satire. The data instead show consistent-although statistically insignificant-gains in political efficacy with the use of satire.}

Another way to assess how appropriate satire might be for teaching political science is to ask the students themselves what they think of its use in class. Although scholars have cautioned against using only student self-reports to evaluate teaching methods (Baumgartner and Morris 2008a; Beavers 2011; Hollander 1995), their responses can provide some insight into how the teaching is received. Students in the satire condition were asked three questions regarding the use of satire in the class: whether the satire helped them to understand the concepts, whether it made the class more enjoyable, and whether they would recommend it for future iterations of the course. Responses to these questions were rescaled on a single three-point scale; mean responses from the in-person and online satire classes are presented in figure 2. The differences in the mean scores between the online and in-person classes are indicated above each set of columns in the figure.

The data indicate a largely positive response to the use of satire across both modes of instruction, with more positive survey responses

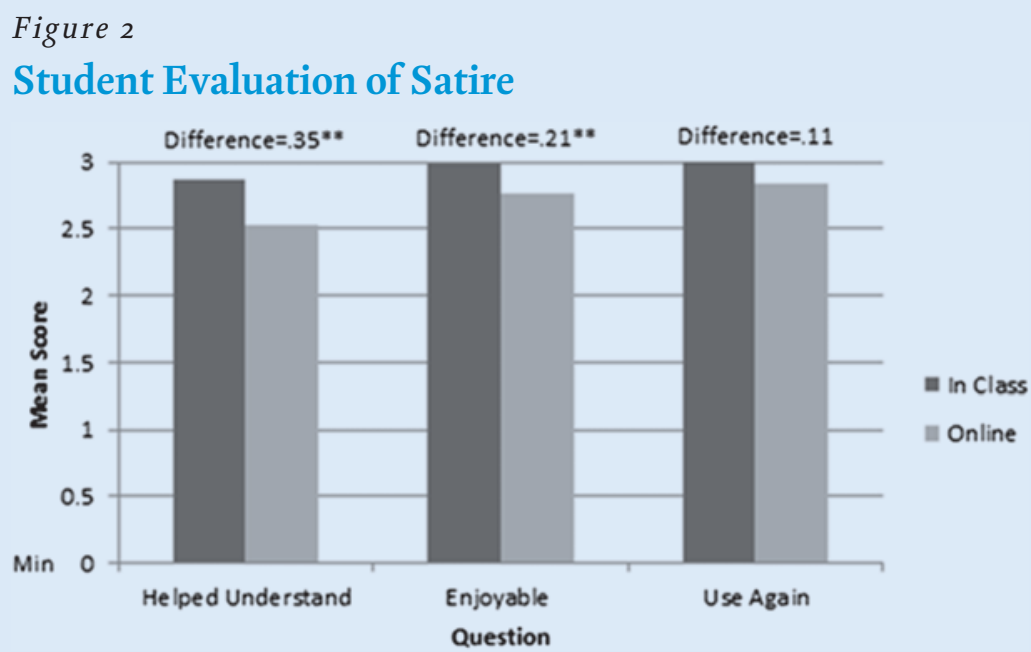

Two-tailed t-tests were conducted to determine whether the differences in means identified above each set of columns were significant, ${ }^{* *} p<0.01$.
Compared to the in-person classes, there also was a greater percentage of women in the online classes (i.e., $63 \%$ to $42 \%$ ). It may be that online students-who are more likely to have heavier work and family obligations compared to students who attend class in person (Kramarae 2001)-see satire as optional or as a waste of time. One online student said, "Working full time and attending school full time, I just didn't have the time available to fully utilize the satire element of the course." Another commented, "I don't really see the point of having this." It is important, however, that online students did not recommend removing the satire from the class; it appears that they simply did not have or take as much time to engage with it.

In all, 90 students across five satire courses responded to the post-survey; a few representative comments are included herein to reinforce the supportive numbers in figure 2. For instance, one repeated comment-in line with scholarly research (Deiter 200o; Torok, McMorris, and Lin 2004; Ziv 1988)-was that the satire helped the students to learn and remember the material. As one student stated, "the satirical articles help to provide an easier way to remember the material. When something is funny, it is much easier to recall both that and the material that was read before and after." Another representative comment was: "I really enjoyed [the satire]; it made a lot of the material more relatable and also made it easier to remember certain terms."

Student comments also illustrate strong support for the use of satire because it led to greater enjoyment of the course. A common sentiment was that the satire, as stated by one student, "made the course less boring and really more entertaining than others." Other students' comments also provided insight into how their views of satire changed throughout the course. Many reported that they were initially unfamiliar with satire and/ or its political meanings, stating, for instance, "I always enjoyed it but never really understood how to read it for more than a laugh." The consistent 
critical analysis of satire appears to have impacted not only how students interpreted the satire as part of the course materials but also their experience with satire outside of the classroom. As one student exclaimed, "It's changed the way I watch The Daily Show and The Colbert Report. Thanks!"

\section{DISCUSSION AND CONCLUSION}

The results of this study indicate that the potential risk of satire as a disillusioning damper on political efficacy is not found when the material is presented regularly, critically, and from multiple sources. The experiment reveals that using satire to teach introductory political science did not result in a decline in political efficacy. Indeed, in the case of in-person classes, efficacy levels were higher in the satire class than in the control class. Although the increased efficacy scores are not significant, it is possible that political satire may keep students' attention, thereby improving efficacy indirectly, especially in traditional classroom settings. As one student stated, "I feel that the satire in class made the class much more enjoyable. The satire kept me awake in class and not once did I ever feel like falling asleep." Satire may not be appropriate for every instructor or every class, but the student endorsements from this study prompt consideration of a trial adoption. At the very least, the evidence presented in this article suggests that we should not avoid satire because of concerns about disengaging and disillusioning students.

As with many pedagogical studies, the data presented in this article are limited; to understand the effects of satire, we need to collect data on its use across a broader range of students. One way to do this may be by coordinating instructors across multiple campuses and similarly implementing satire across courses. For now, those instructors interested in experimenting with satirical materials in their courses can access the satirical resource repository on the author's website at www.rebeccaglazier.net/satirical-resource-repository.This searchable repository is a resource to help instructors select satire materials that will complement other course content. They can search or browse satire that is organized by subfield and topic and listed with the title, date, direct link, and a brief description.

The approach to teaching with satire presented in this article-that is, using diverse satire in a consistent and critical way-appears to have benefits. It does not decrease political efficacy as some expected but instead may actually increase it. This finding, in conjunction with the overwhelmingly positive student feedback, provides an invitation to political science instructors to "get in on the joke" and use satire in their teaching.

\section{ACKNOWLEDGMENTS}

The author thanks John Berg, Amber Boydstun, Michelle Deardorff, Jessica Feezell, Joe Giammo, Fletcher McClellan, and Doug Reed for helpful comments on previous versions of this article. Sincere thanks are also warranted for Jessica Cone, Tristan Thibodeaux, Joshua Thomsen, and the many other students who contributed to the Satirical Resource Repository. Any and all mistakes and oversights remain the author's.

\section{NOTES}

1. I once had a student-thinking it was an actual news item-express outrage at the satirical article, "Bill of Rights Trimmed Down to a Manageable Six."

2. The author's website, www.rebeccaglazier.net/satirical-resource-repository, contains a list of all satirical materials used in the satire condition, as well as other satirical materials. The purpose is to provide readers with a sampling of the materials used to better understand the teaching experiment and a resource for instructors interested in incorporating satire in their courses.

3. The complete assignments are available on the author's website: www. rebeccaglazier.net/satirical-resource-repository.

4. The full wording for all questions presented in this article is available on the author's website: www.rebeccaglazier.net/satirical-resource-repository.

5. The full model results are available from the author on request.

\section{R E F E R E N C E S}

Baek, Young Min, and Magdalena E. Wojcieszak. 2009. "Don't Expect Too Much! Learning from Late-Night Comedy and Knowledge Item Difficulty." Communication Research 36 (6): 783-809.

Baum, Matthew A. 2003. "Soft News and Political Knowledge: Evidence of Absence or Absence of Evidence?” Political Communication 20 (2): 173-90.

Baumgartner, Jody C. 2008. "Polls and Elections: Editorial Cartoons 2.0: The Effects of Digital Political Satire on Presidential Candidate Evaluations." Presidential Studies Quarterly 38 (4): 735-58.

Baumgartner, Jody, and Jonathan S. Morris. 2006. "The Daily Show Effect." American Politics Research 34 (3): 341-67.

Baumgartner, Jody, and Jonathan S. Morris. 2008a. "Jon Stewart Comes to Class: The Learning Effects of America (The Book) in Introduction to American Government Courses." Journal of Political Science Education 4 (2): 169-86.

Baumgartner, Jody, and Jonathan S. Morris. 20o8b. “One 'Nation,' Under Stephen? The Effects of The Colbert Report on American Youth." Journal of Broadcasting $\mathcal{E}$ Electronic Media 52 (4): 622-43.

Baym, Geoffrey. 2005. "The Daily Show: Discursive Integration and the Reinvention of Political Journalism.” Political Communication 22 (3): 259-76.

Bean, John C., and Maryellen Weimer. 2011. Engaging Ideas: The Professor's Guide to Integrating Writing, Critical Thinking, and Active Learning in the Classroom. Hoboken, NJ: John Wiley \& Sons.

Beavers, Staci L. 2011. "Getting Political Science in on the Joke: Using The Daily Show and Other Comedy to Teach Politics." PS: Political Science and Politics 44 (02): 415-19.

Bibel, Sara. 2013. Late Night TV Ratings for February 25-March 1, 2013 [cited March 9 2013]. Available at http://tvbythenumbers.zap2it.com/2013/03/o7/late-night-tvratings-for-february-25-march-1-2013/172332.

Cao, Xiaoxia. 2010. "Hearing It from Jon Stewart: The Impact of The Daily Show on Public Attentiveness to Politics." International Journal of Public Opinion Research 22 (1): $26-46$.

Cao, Xiaoxia, and Paul R. Brewer. 2008. "Political Comedy Shows and Public Participation in Politics.” International Journal of Public Opinion Research 20 (1): 90-9.

Conners, Joan L. 2005. "Visual Representations of the 2004 Presidential Campaign: Political Cartoons and Popular Culture References." American Behavioral Scientis 49 (3): 479-87.

Craig, Stephen C., Richard G. Niemi, and Glenn E. Silver. 1990. "Political Efficacy and Trust: A Report on the NES Pilot Study Items." Political Behavior 12 (3): 289-314.

Cutbirth, Joe Hale. 2011. "Satire as Journalism: The Daily Show and American Politics at the Turn of the Twenty-First Century." PhD Dissertation, Political Science, New York: Columbia University.

Deiter, Ron. 200o. "The Use of Humor as a Teaching Tool in the College Classroom." North American Colleges and Teachers of Agriculture Journal 44 (2): 20-7.

Diamond, Matthew. 2002. "No Laughing Matter: Post-September 11 Political Cartoons in Arab/Muslim Newspapers." Political Communication 19 (2): 251-72.

Duff, John Wight. 1936. Roman Satire: Its Outlook on Social Life. Berkeley: University of California Press.

Edelman, Murray. 1995. Constructing the Political Spectacle. Chicago: University of Chicago Press.

Elder, Charles D., and Roger W. Cobb. 1983. The Political Uses of Symbols. London: Longman.

Fowler, James H. 2008. "The Colbert Bump in Campaign Donations: More Truthful than Truthy." PS: Political Science and Politics 41 (3): 533-9.

Fox, Julia R., Glory Koloen, and Volkan Sahin. 2007. "No Joke: A Comparison of Substance in The Daily Show with Jon Stewart and Broadcast Network Television Coverage of the 2004 Presidential Election Campaign." Journal of Broadcasting $\mathcal{E}$ Electronic Media 51 (2): 213-27.

Gorman, Bill. 2011. "The Daily Show with Jon Stewart Tops the Competition in May as the Most-Watched Late-Night Talk Show Among Persons 18-49, Persons 18-34, Persons 18-24, Men 18-34, and Men 18-24," June 2, 2011 [cited August 8, 2011]. Available at http://tvbythenumbers.zap2it.com/2011/06/02/the-daily-showwith-jon-stewart-tops-the-competition-in-may-as-the-most-watched-late-nighttalk-show-among-persons-18-49-persons-18-34-persons-18-24-men-18-34-andmen-18-24/94506. 
Guggenheim, Lauren, Nojin Kwak, and Scott W. Campbell. 2011. "Nontraditional News Negativity: The Relationship of Entertaining Political News Use to Political Cynicism and Mistrust." International Journal of Public Opinion Research 23 (3) 287-314.

Hammett, Daniel, and Charles Mather. 2010. "Beyond Decoding: Political Cartoons in the Classroom." Journal of Geography in Higher Education 35 (1): 103-19.

Hoffman, Lindsay H., and Tiffany L. Thomson. 2009. "The Effect of Television Viewing on Adolescents' Civic Participation: Political Efficacy as a Mediating Mechanism." Journal of Broadcasting \& Electronic Media 53 (1): 3-21.

Hoffman, Lindsay H., and Dannagal G. Young. 2011. "Satire, Punch Lines, and the Nightly News: Untangling Media Effects on Political Participation." Communication Research Reports 28 (2): 159-68.

Hollander, Barry A. 1995. "The New News and the 1992 Presidential Campaign: Perceived vs. Actual Political Knowledge." Journalism and Mass Communication Quarterly 72 (4): 786-98.

Jones, Jeffrey P. 2005. Entertaining Politics: New Political Television and Civic Culture New York: Rowman \& Littlefield.

Jones, Jeffrey P. 2010. Entertaining Politics: Satiric Television and Political Engagement, Second Edition. New York: Rowman \& Littlefield.

Journell, Wayne. 2011. "Teaching Politics in Secondary Education: Analyzing Instructional Methods from the 2008 Presidential Election." The Social Studies 102 (6): 231-41.

Kramarae, Cheris. 2001. The Third Shift: Women Learning Online. University of Michigan: American Association of University Women Educational Foundation.

LaMarre, Heather L., Kristen D. Landreville, and Michael A. Beam. 2009. "The Irony of Satire." The International Journal of Press/Politics 14 (2): 212-31.

Lee, Hoon. 2012. "Communication Mediation Model of Late-Night Comedy: The Mediating Role of Structural Features of Interpersonal Talk Between Comedy Viewing and Political Participation." Mass Communication and Society 15 (5): 647-71.

Mann, Jill. 1973. Chaucer and Medieval Estates Satire: The Literature of Social Classes and the General Prologue to The Canterbury Tales. Cambridge: Cambridge University Press.

McBeth, Mark K. and Randy S. Clemons. 2011 "Is Fake News the Real News? The Significance of Stewart and Colbert for Democratic Discourse, Politics, and Policy." In The Stewart/Colbert Effect: Essays on the Real Impacts of Fake News, ed. A. Amarasignam and R. W. McChesney. 79-98. . Jefferson, NC: McFarland and Company.

Meddaugh, Priscilla Marie. 2010. "Bakhtin, Colbert, and the Center of Discourse: Is There No 'Truthiness' in Humor?" Critical Studies in Media Communication 27 (4): 376-90.

Moy, Patricia, Michael A. Xenos, and Verena K. Hess. 2005. "Communication and Citizenship: Mapping the Political Effects of Infotainment." Mass Communication and Society 8 (2): 111-31.
Ogborn, Jane, and Peter Buckroyd. 2001. Satire. New York: Cambridge University Press.

Paletz, David L. 2002. The Media in American Politics: Contents and Consequences. Boston: Addison-Wesley.

Pew Research Center. 2004. Cable and Internet Loom Large in Fragmented Politica News Universe. Pew Research Center for the People and the Press [cited May 10 2013]. Available at www.people-press.org/2004/01/11/cable-and-internet-loomlarge-in-fragmented-political-news-universe.

Pew Research Center. 2007. "Public Knowledge of Current Affairs Little Changed by News and Information Revolutions." Pew Research Center for the People and the Press. [cited August 18, 2011]. Available at http://www.people-press.org/files/ legacy-pdf/319.pdf.

Pew Research Center. 2008. "Journalism, Satire or Just Laughs? The Daily Show with Jon Stewart Examined.” The Pew Research Center's Project for Excellence in Journalism. [cited August 18, 2011]. Available at http://www.journalism.org/files/ legacy/Daily\%2oShow\%2oPDF_3.pdf.

Polk, Jeremy, Dannagal G. Young, and R. Lance Holbert. 2009. "Humor Complexity and Political Influence: An Elaboration Likelihood Approach to the Effects of Humor Type in The Daily Show with Jon Stewart." Atlantic Journal of Communication 17 (4): 202-19.

Stark, Craig. 2003. "What, Me Worry?': Teaching Media Literacy through Satire and Mad Magazine." The Clearing House: A Journal of Educational Strategies, Issues and Ideas 76 (6): 305-9.

Teten, Ryan Lee. 2010. "When in Rome, Do as Jon Stewart Does: Using America: The Book as a Textbook for Introductory-Level Classes in American Politics." Journal of Political Science Education 6 (2): 163-87.

The Onion. 1999. "American People Ruled Unfit to Govern." 46 (26). April 14. [cited August 1, 2011]. Available at http://www.theonion.com/articles/american-peopleruled-unfit-to-govern,748/.

Tisdale, Elkanah. 1812. The Gerry-Mander. Boston: The Boston Gazette.

Toohey, Susan. 1999. Designing Courses for Higher Education. Buckingham: The Society for Research into Higher Education and Open University Press.

Torok, Sarah E., Robert F. McMorris, and Wen-Chi Lin. 2004. "Is Humor an Appreciated Teaching Tool? Perceptions of Professors' Teaching Styles and Use of Humor." College Teaching 52 (1): 14-20.

Tsfati, Yariv, Riva Tukachinsky, and Yoram Peri. 2009. "Exposure to News, Politica Comedy, and Entertainment Talk Shows: Concern about Security and Political Mistrust." International Journal of Public Opinion Research 21 (4):399-423.

Young, Dannagal Goldthwaite. 2004. "Daily Show Viewers Knowledgeable about Presidential Campaign, National Annenberg Election Survey Shows.” Annenberg Public Policy Center, news release, September 21.

Ziv, Avner. 1988. "Teaching and Learning with Humor: Experiment and Replication." The Journal of Experimental Education 57 (1): 5-15 